\title{
Effect of different drying treatments on concentration of curcumin in raw Curcuma longa $\mathrm{L}$.
}

\author{
${ }^{1}$ Raza, A., ${ }^{2}$ Ali, M. A., ${ }^{1,3 *}$ Yusof, Y. A., ${ }^{2}$ Nasir, A. and ${ }^{4}$ Muneer, S. \\ ${ }^{1}$ Department of Process and Food Engineering, Faculty of Engineering, \\ Universiti Putra Malaysia, 43400, UPM Serdang, Selangor, Malaysia. \\ ${ }^{2}$ Department of Structures and Environmental Engineering, Faculty of Agricultural Engineering and \\ Technology, University of Agriculture, Faisalabad, 38000, Punjab, Pakistan. \\ ${ }^{3}$ Laboratory of Halal Services, Halal Products Research Institute, Universiti Putra Malaysia, \\ 43400 Selangor, Malaysia. \\ ${ }^{4}$ Government College University Faisalabad, 38000, Punjab, Pakistan.
}

\begin{abstract}
Article history:
Received: 21 May 2018

Received in revised form: 3

July 2018

Accepted: 13 July 2018

Available Online: 6

November 2018

Keywords:

Curcumin,

Sun drying,

Shade drying,

Convection oven drying,

Hot-air drying,

Solar tunnel drying
\end{abstract}

DOI:

https://doi.org/10.26656/fr.2017.2(6).109

\begin{abstract}
Curcuma longa L., commonly known as turmeric, is a member of the ginger family (Zingiberaceae), native to Southwest India. Curcumin is the active ingredient of the turmeric. In traditional Indian medicine, turmeric has been used to treat stomach and liver ailments, as well as topically to heal sores, for its supposed antimicrobial property. The curcumin is believed to have a wide range of biological effects including antiinflammatory, antioxidant, antitumor, antibacterial, and antiviral activities, which indicate potential in clinical medicine. In conventional processing of turmeric, raw turmeric rhizomes boiled and dried under direct sunlight for 1-4 hrs and 25-30 days, respectively although which is highly sensitive to the heat and sunlight. This work described the effect of different drying treatments including shade, direct sunlight, solar dryer, convection oven and hot-air drying on the concentration of curcumin. The Reflux method was used to analyse the concentration of curcumin in turmeric powder prepared under different drying treatments. The results had shown that without boiling turmeric rhizomes took too much time to reach the final moisture contents below $10 \%$ in all drying treatments which was not feasible economical and hygienically. The optimum conditions for drying of turmeric rhizomes were $1 \mathrm{hr}$ boiling and drying at $70^{\circ} \mathrm{C}$ in hot-air dryer.
\end{abstract}

\section{Introduction}

A prestigiously beneficial food commodity by the nature that exhibits remarkable medicinal properties is Curcuma longa, Linn, which is commonly known as turmeric and belongs to ginger family (Zingiberaceae). It is perennially cultivated in red soils to clay loam, sandy loam and light black soils with favourable weather condition of tropical and sub-tropical regions of Southeast Asia. It requires a thriving temperature of 20$30^{\circ} \mathrm{C}$ with considerable amount of irrigation water (Yadav and Tarun, 2017). The global production of turmeric ranged about 1.1-1.15 million tons/year (Kanungo, 2016) in which India was leading contributor with $82 \%$ productivity share followed by China (8\%), Myanmar (4\%), Bangladesh (3\%), Nigeria (3\%) and 2\% by rest of others (Moghe et al., 2012). Turmeric is commonly used as a food additive, colouring agent, cosmetic ingredient and especially in sub-continent region, it is also used in religious ceremonies especially among Hindu community of India. Most importantly, turmeric has a vast 5000 years of medicinal history to be prescribed abundantly as a medicinal herb for various human ailments that are now being validated by modern science (Prashanti, 2010).

Curcuminoids or commonly termed as curcumin are the main phytoconstituents found approximately 1-6\% by dry weight in the form of diarylheptanoids (Niranjan et al., 2013) and responsible for the light-yellow colour of turmeric. It was first isolated in 1815 and chemically analysed by Roughley and Whiting in 1973. Curcumin was melted at $176-177^{\circ} \mathrm{C}$, produced a reddish-brown salt with alkali and soluble in ketone, ethanol, acetic acid, alkali and chloroform (Chattopadhyay et al., 2004). The booming nutraceutical applications of curcumin and advents in in-vitro testing led to flourishing publication of manuscripts on its biological activities as antiinflammatory, antifungal, antibacterial, anti-HIV, antidiabetic, nematocidal, antimutagenic, 
antifibrinogenic, antiparasitic, radioprotective, wound healing, antispasmodic, lipid-lowering (Niranjan et al., 2008), antioxidant (Panahi et al., 2015), anticarcinogenic, immunomodulating (Yue et al., 2010) and Alzheimer's disease ( $\mathrm{Hu}$ et al., 2015). The effective but non-selective therapeutic perspective had made curcumin a potential source of future breakthrough in the treatment of complex diseases. One can envisage the significantly increasing role of curcumin in human ailments by the sale of its supplements as food additives, valuing more than \$20 million in 2014, in the United States (Majeed, 2015).

Turmeric, before entering the market as a stable commodity, undergoes a number of post-harvest processing operations viz. curing, drying, polishing, colouring and milling of rhizomes. Conventionally, mother and finger rhizomes are separated and cooked (45 -60 mins $)$ in boiling water $\left( \pm 100^{\circ} \mathrm{C}\right)$, sometimes with the mixing of alkaline solution. Open sun drying is applied on cured rhizomes for $12-15$ days and then dried rhizomes are polished to remove dull and rough outer surface. Polished rhizomes are then coloured to enhance the appearance and finally, ground to produce uniform powder product (Shinde et al., 2011; Gitanjali et at., 2014; Pethkar et al., 2017). Medicinally, curcumin is the most important constituent of turmeric, but it is lost about 27-53\% (Suresh et al., 2017) due to heat processing. Due to high light sensitivity (Geethanjali et $a l ., 2016)$, it is further lost in commonly practiced open sun drying method. Surprisingly, curcumin contents in various commercial turmeric powders from all over the world range from 0.58 to $1.2 \%$ on an average and in curry powders, it is less than 1\% (Reema et al., 2016).

Turmeric contains moisture $(70-80 \%)$ at the time of harvest which should be reduced to a safe limit for milling (10\%) and storage (6\%) (Singh et al., 2010). Several gadgets were developed for the processing of turmeric, but all were heat treatment based and resulted, no doubt in reduced curing and drying time but no weighty curcumin preservation was achieved. To date, there is no scientific research is reported in Pakistan on curcumin recovery during the post-harvest processing of turmeric. Therefore, this study was taken up to compare and analyze the effect of different drying techniques on the concentration of curcumin in Curcuma longa, $L$.

\section{Materials and methods}

\subsection{Raw materials}

Freshly harvested turmeric rhizomes (Kesari variety) of were procured from turmeric market of District Kasur, Punjab, Pakistan which was capable to contribute $80 \%$ of total turmeric produce in Pakistan with 30569 tons/year
(Anwar et al., 2012). The experimental procedures and analysis were done at Faculty of Agricultural Engineering and Technology, University of Agriculture Faisalabad, Pakistan.

\subsection{Sun and shade dry}

Turmeric rhizomes were spread evenly on a clean sheet and subjected under open sun drying and shade drying conditions. Rhizomes were turned over after regular intervals to for constant drying rate (Ali et al., 2017). Samples were heaped during night time in case of open sun drying to avoid moisture fall in the night. Moisture loss at 6-hr intervals for both drying treatments were examined until a constant value obtained. Drying times (days) for both approaches were also noted.

\subsection{Convection oven drying}

A lab-scale convection oven was used to reduce the moisture contents of rhizomes at $60^{\circ} \mathrm{C}, 70^{\circ} \mathrm{C}, 80^{\circ} \mathrm{C}$ and $90^{\circ} \mathrm{C}$ oven temperatures. One kilogram of rhizomes was uniformly spread over the oven tray and moisture loss was observed at 1-hr interval until optimum moisture contents were achieved. All experiments were done in triplicates.

\subsection{Hot air drying}

Turmeric rhizomes were dried in a six-tray lab scale hot air dryer. Rhizomes were spread equally on each tray and hot air dryer was operated at $60^{\circ} \mathrm{C}, 70^{\circ} \mathrm{C}, 80^{\circ} \mathrm{C}$ and $90^{\circ} \mathrm{C}$ temperatures with a constant air flow rate of $5 \mathrm{~m} / \mathrm{s}$. Moisture contents were noted after every $1 \mathrm{hr}$ until a constant mass of rhizomes was obtained.

\subsection{Solar tunnel drying}

A solar tunnel dryer placed at Solar Energy Park, Faculty of Agricultural Engineering and Technology, University of Agriculture Faisalabad was used to determine the effect for desired treatment. Samples were placed in single layer evenly on the trays of solar tunnel dryer. Moisture content $(\%)$, air flow velocity $(\mathrm{m} / \mathrm{s})$ and temperature of dryer $\left({ }^{\circ} \mathrm{C}\right)$ were recorded constantly at 1 $\mathrm{hr}$ interval until the final moisture contents were obtained.

\subsection{Curcumin determination}

Reflux method, described by Geethanjali et al. (2016), was used to determine the curcumin concentration of the turmeric samples. About $75 \mathrm{~mL}$ acetone was taken in round flask of $250 \mathrm{~mL}$ and $1 \mathrm{~g}$ of turmeric powder sample of each treatment was refluxed for $1 \mathrm{hr}$. It was filtered and diluted with distilled water to make $200 \mathrm{~mL}$ solution from which further $1 \mathrm{~mL}$ was taken and diluted to made $100 \mathrm{~mL}$ in a standard flask. 
The flasks were wrapped with dark coloured tape and dark conditions maintained since curcumin is light sensitive. The UV spectrometer (JENWAY $6305 \mathrm{UV} /$ Vis.) was used to measure the wavelength of the solution under $420 \mathrm{~nm}$. The measured absorptions of turmeric samples were compared with the standard value and curcumin concentrations were determined using the formula:

$$
\operatorname{Curcumin}(\%)=\left[\frac{D_{s} \times A_{s}}{100 \times W_{s} \times 1650}\right] \times 100
$$

Where $D_{s}, A_{s}, W_{s}$ and 1650 is the dilution volume of the sample (i.e. $200 * 100=20000 \mathrm{~mL}$ ), absorbance of the sample, weight of the sample $(\mathrm{g})$, and standard value calculated by experts respectively.

\section{Results and discussion}

Table 1. Effect of different drying treatments on the concentration of curcumin in turmeric without boiling.

\begin{tabular}{cccc}
\hline Drying treatment & Time & Curcumin (\%) \\
\hline Sun drying without boiling & 43 days & $1.40 \pm 013$ \\
\hline Shade drying without boiling & 76 days & $2.16 \pm 0.11$ \\
\hline \multirow{3}{*}{$\begin{array}{c}\text { Convection oven } \\
\text { drying }\end{array}$} & at $60^{\circ} \mathrm{C}$ & $45 \mathrm{hrs}$ & $2.93 \pm 0.14$ \\
\cline { 2 - 4 } & at $70^{\circ} \mathrm{C}$ & $27 \mathrm{hrs}$ & $2.15 \pm 0.11$ \\
\cline { 2 - 4 } & at $80^{\circ} \mathrm{C}$ & $18 \mathrm{hrs}$ & $2.06 \pm 0.16$ \\
\cline { 2 - 4 } & at $90^{\circ} \mathrm{C}$ & $06 \mathrm{hrs}$ & $1.73 \pm 0.12$ \\
\hline \multirow{4}{*}{ Hot air drying } & at $60^{\circ} \mathrm{C}$ & $41 \mathrm{hrs}$ & $2.85 \pm 0.11$ \\
\cline { 2 - 4 } & at $70^{\circ} \mathrm{C}$ & $21 \mathrm{hrs}$ & $2.97 \pm 0.19$ \\
\cline { 2 - 4 } & at $80^{\circ} \mathrm{C}$ & $11 \mathrm{hrs}$ & $1.92 \pm 0.13$ \\
\cline { 2 - 4 } & at $90^{\circ} \mathrm{C}$ & $04 \mathrm{hrs}$ & $1.84 \pm 0.15$ \\
\hline \multicolumn{2}{c}{ Solar tunnel drying } & $37 \mathrm{days}$ & $1.68 \pm 0.08$ \\
\hline
\end{tabular}

Table 1 shows the effect of different drying conditions on drying time to reach moisture content less than $10 \%$ (wet basis) and concentration of curcumin in turmeric samples without boiling. As shown in Table 1, shade drying took a maximum time of 76 days to reach moisture content below $10 \%$ followed by sun drying. This long drying duration had a negative impact on curcumin concentration. As the drying duration increases, the curcumin concentration decreases. In the case of convection oven and hot-air drying, the drying

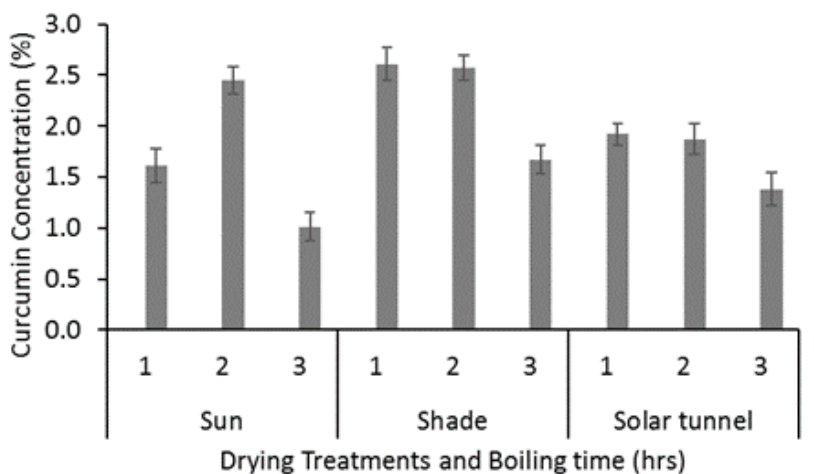

trend is not same as shade and sun drying. Drying time and curcumin concentration decrease as temperature increases which clearly indicates that temperature has direct effect on curcumin concentration in turmeric either in convection oven or hot-air drying.

Figure 1 shows the combined effect of boiling for 1 to $3 \mathrm{hrs}$ and different drying treatments on turmeric samples. It is clearly indicated that the drying time reduces almost 4 to 5 times when turmeric rhizomes were dried for 1 to $3 \mathrm{hrs}$. The curcumin concentration was increased from $1.40 \pm 013$ to $1.61 \pm 0.17,1.45 \pm 0.13$ and $1.01 \pm 0.18$ during first, second and third hrs of boiling in case of sun drying treatment (Figure 1). The above-mentioned trend was the same for all other drying treatments including sun, convection oven, and hot-air drying. These results showed that boiling has also a significant effect on curcumin concentration followed by drying temperature. Suresh et al. (2017) also reported that curcumin may damage due to boiling while Geethanjali et al. (2016) concluded that curcumin is highly light-sensitive nutrient of turmeric.

Figure 2 shows the effect of drying temperature on drying time and curcumin concentration. The bars clearly indicated that drying time reduced linearly with respect to increase in temperature. While curcumin concentration also decreased with an increase in drying temperature. In case of boiling time, the curcumin concentration increased at $1 \mathrm{hr}$ boiling but curcumin concentration decreased when drying time increased for $2-3 \mathrm{hrs}$

As the boiling time increased the drying time decreased but curcumin concentration decreased as the boiling time increased. The highest concentration of curcumin was found during hot-air drying at $70^{\circ} \mathrm{C}$ temperature and $1 \mathrm{hr}$ boiling which means hot-air at $70^{\circ} \mathrm{C}$ temperature are the optimum drying conditions for turmeric rhizomes (Figure 3). Direct and indirect sunlight has highest effect on curcumin concentration as shown from results the sun drying and solar tunnel

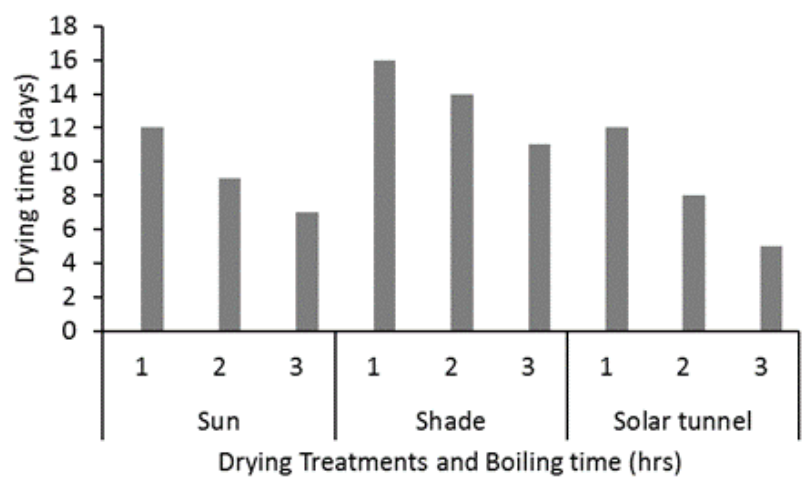

Figure 1. Effect of conventional drying treatments and boiling time on drying period and curcumin concentration in raw turmeric rhizomes. 

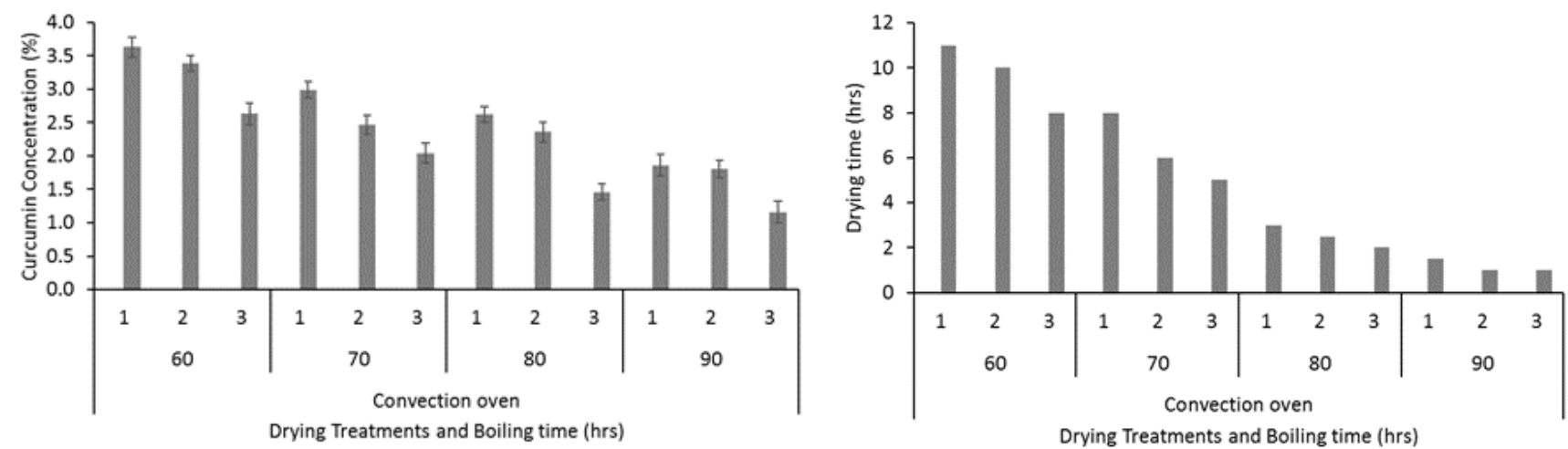

Figure 2. Effect of convection oven drying treatment and boiling time on drying period and curcumin concentration in raw turmeric rhizomes.
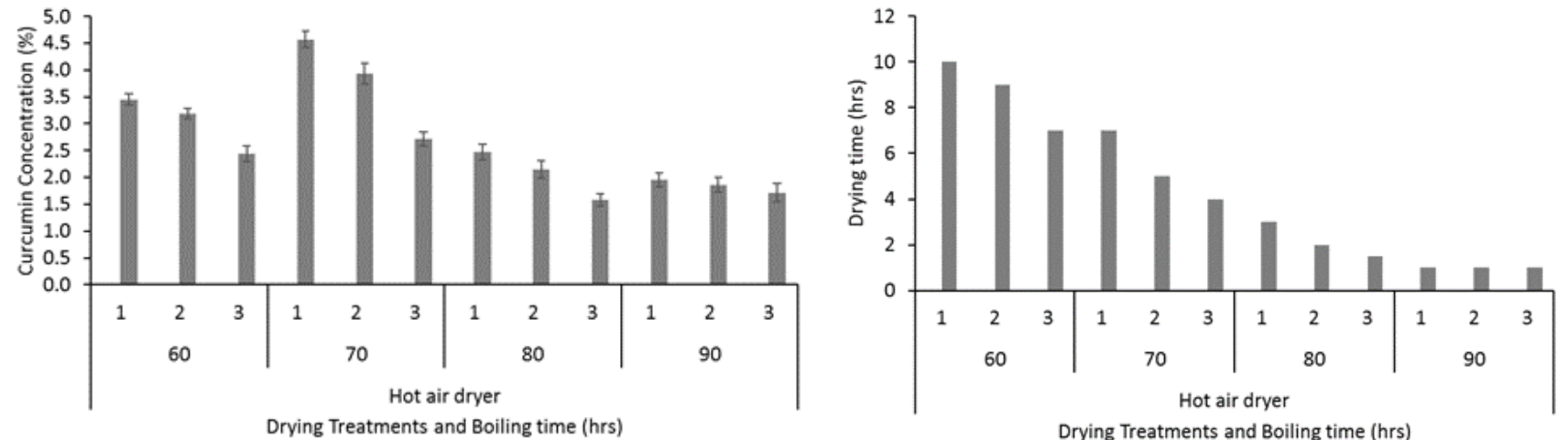

Figure 3. Effect of hot air-drying treatment and boiling time on drying period and curcumin concentration in raw turmeric rhizomes.

drying had a minimum concentration of curcumin both whether boiling or without boiling turmeric rhizomes.

\section{Conclusion}

Curcumin is medicinally most important constituent of turmeric but it is heat and light sensitive. Direct sunlight affects the curcumin concentration significantly followed by drying temperature then drying duration. Boiling of turmeric rhizomes is before drying can reduce drying period up to 4 times but also reduces the curcumin concentration. Hot air drying treatment at $70^{\circ} \mathrm{C}$ and $1 \mathrm{hr}$ boiling time are the optimum drying conditions for turmeric rhizomes in terms of minimum drying time and maximum curcumin concentration.

\section{Acknowledgement}

The authors would like to acknowledge the financial support provided by Endowment Funds Secretariat (U.S.A.) and Universiti Putra Malaysia (UPM) for academic coordination.

\section{References}

Ali, M.A., Yusof, Y.A., Chin, N.L. and Ibrahim, M.N. (2017). Processing of Moringa leaves as natural source of nutrients by optimization of drying and grinding mechanism. Journal of Food Process
Engineering, 40(6),12583-95. https:// doi.org/10.1111/jfpe. 12583

Anwar, W., Khan, S.N., Tahira J.J. and Suliman, R. (2012). Parthenium Hysterophorus: An emerging threat for Curcuma longa fields of Kasur district, Punjab, Pakistan. Pakistan Journal of Weed Science Research, 18(1), 91-97.

Chattopadhyay, I., Biswas, K., Bandyopadhyay, U. and Banerjee R.K. (2004). Turmeric and curcumin: Biological actions and medicinal applications. Current Science, 87(1), 44-53.

Geethanjali, A., Lalitha, P. and Jannathul, F. (2016). Analysis of curcumin content of turmeric samples from various states of India. International Journal of Pharma and Chemical Research, 2(1), 55-62.

Gitanjali, J., Venkatachalam, P. and Subramanian, P. (2014). Development of high efficient combustion system for turmeric boiling. Journal of Environmental Research and Development, 9(1), 6774.

Shinde, G.U., Kamble, K.J., Harkari, M.H. and More, G.R. (2011). Process optimization in turmeric heat treatment by design and fabrication of blancher. 2011 International Conference on Environmental and Agriculture Engineering. IPCBEE 15(2011), 36-41.

Hu, S., Maiti, P., Ma, Q., Zuo, X., Jones, M.R., Cole, G.M. and Frautschy, S.A. (2015). Clinical 
development of curcumin in neurodegenerative disease. Expert Review Neurotherapeutics, 15(6), 629-637. https:// doi.org/10.1586/14737175.2015.1044981

Kanungo, S. (2016). Trend analysis of turmeric exported from India and associated foreign earnings. International Journal of Research in Economics and Social Sciences, 6(11), 99-105.

Majeed, S. (2015). The state of the curcumin market. Natural Products Insider. Retrieved on December 2015 from Natural Products Insider website: https:// www.naturalproductsinsider.com/herbs-botanicals/ state-curcumin-market.

Moghe, S.M., Zakiuddin, K.S. and Arajpure, V.G. (2012). Design and development of turmeric polishing machine. International Journal of Modern Engineering Research, 2(6), 471-4713.

Niranjan, A. and Prakash, D. (2008). Chemical constituents and biological activities of turmeric (Curcuma longa 1.) - a review. Journal of Food Science and Technology-Mysore-, 45(2), 109-116.

Niranjan, A., Singh, S., Dhiman, M. and Tewari, S.K. (2013). Biochemical composition of Curcuma longa 1. Accessions. Analytical Letters, 46(7), 1069-1083. https://doi.org/10.1080/00032719.2012.751541

Panahi, Y., Hosseini, M.S., Khalili, N., Naimi, E., Majeed, M. and Sahebkar, A. (2015). Antioxidant and anti-inflammatory effects of curcuminoidpiperine combination in subjects with metabolic syndrome: A randomized controlled trial and an updated meta-analysis. Clinical Nutrition, 34(6), 1101-1108.

https://doi.org/10.1016/ j.clnu.2014.12.019

Pethkar, R., Ujwal, A., Siddhesh, K., Avadhoot K. and Shrikant, K. (2017). Study of design and development of turmeric processing unit: a review. International Journal of Innovations in Engineering Research and Technology, 4(3), 128-134.

Prashanti, D.M.S. (2010). Turmeric: The Ayurveda spice of life. $2^{\text {nd }}$ ed, p. 11-12. India: Vidiyasagar Publications.

Reema, F.T., Dennis, D.H., Wael, K.A. and Cheryl, L.R. (2016). Curcumin content of turmeric and curry powders. Nutrition and Cancer, 55(2), 126-131.

Singh, G., Arora, S. and Kumar, S. (2010). Effect of mechanical drying conditions on quality of turmeric powder. Journal or Food Science and Technology, 47(3), 347-350. https://doi.org/10.1007/s13197-0100057-6

Suresh, D., Manjunatha, H. and Srinivasan, K. (2017). Effect of heat processing of spices on the concentrations of their bioactive, principles: turmeric
(Curcuma longa), red pepper (Capsicum annuum) and black pepper (Piper nigrum). Journal of Food Composition and Analysis, 20(3-4), 346-351.

Yadav, R.P. and Tarun, G. (2017). Versatility of turmeric: A review the golden spice of life. Journal of Pharmacognosy and Phytochemistry, 6(1), 41-46.

Yue, G.G., Chan, B.C., Hon, P.M., Lee, M.Y., Fung, K.P., Leung, P.C. and Lau, C.B. (2010). Evaluation of in vitro anti-proliferative and immunomodulatory activities of compounds isolated from Curcuma longa. Food and Chemical Toxicology, 48(8-9), 2011-2020. https://doi.org/10.1016/j.fct.2010.04.039 